\title{
Preschoolers' vocabulary acquisition in Chile: the roles of socioeconomic status and quality of home environment*
}

\author{
REGINA T. LOHNDORF, HARRIET. J. VERMEER, \\ RODRIGO A. CÁRCAMO AND JUDI MESMAN \\ Leiden University, the Netherlands, and University of Magallanes, Chile
}

(Received 9 Fune 2016 -Revised I 3 Fuly 201 7 -Accepted 24 Fuly 2017)

\begin{abstract}
Preschoolers' vocabulary acquisition sets the stage for later reading ability and school achievement. This study examined the role of socioeconomic status (SES) and the quality of the home environment of seventy-seven Chilean majority and Mapuche minority families from low and lower-middle-class backgrounds in explaining individual differences in vocabulary acquisition of their three-and-a-half-year-old children. Additionally, we investigated whether the relation between SES and receptive and expressive vocabulary was mediated by the quality of the home environment as the Family Investment Model suggests. The quality of the home environment significantly predicted receptive and expressive vocabulary above and beyond ethnicity, SES, parental caregiver status, and quantity of daycare. Furthermore, the quality of the home environment mediated the relation between SES and expressive and receptive vocabulary acquisition.
\end{abstract}

\section{INTRODUCTION}

The Family Investment Model explains how higher socioeconomic status predicts higher levels of parental investment in child development, which in turn predicts more favorable child outcomes (Conger \& Donellan, 2007), such as early language acquisition (e.g. Bus, van IJzendoorn \&

[*] This study was made possible by a grant awarded to the first author by the National Commission for Scientific and Technological Research of Chile (CONICYT, Becas Chile). We would like to thank JUNJI (Junta Nacional de Jardines Infantiles National Council of Daycare Centers) and INTEGRA (National Network of Nursery Schools and Kindergartens) of the Araucanía region for tirelessly supporting our study. We furthermore thank the School of Psychology of the Universidad Autónoma Temuco for their collaboration. Address for correspondence: H. Vermeer, Centre for Child and Family Studies, Leiden University, Wassernaarseweg 52, 2333 AK Leiden, The Netherlands. e-mail: vermeer@FSW.leidenuniv.nl 
Pellegrini, I 995; Rodriguez \& Tamis-LeMonda, 20 I ; Song, Spier \& Tamis-Lemonda, 2013). However, almost all research (96\%) in the field of human behavior and development is based on samples from the so-called Western, educated, industrialized, rich, and democratic countries, which comprise a disturbingly small (12\%) and unrepresentative portion of the world's population. (Henrich, Heine \& Norenzayan, 2010). This is highly problematic, as socioeconomic and cultural context can affect both the manifestations and the inter-relations of key developmental processes (Bornstein, I995; Bornstein, Putnick, Lansford, Deater-Deckard \& Bradley, 20I5). The Family Investment Model is of special relevance for less affluent parts of the world, where socioeconomic disadvantage is often the norm. However, it is unclear whether the same family processes hold up in populations characterized by generally lower socioeconomic conditions and different ethnic backgrounds with their own sets of social customs and cultural parenting practices. Hence it is important to study commonly found relations between family processes and child development outside the Western world to establish whether these patterns of associations are shared cross-culturally, as the universal effects assumption states, or whether cultural differences occur (Norenzayan \& Heine, 2005; Segall, Lonner \& Berry, I998). In the current study, we test the Family Investment Model in the Latin-American cultural context of Chile, examining parental investment in terms of the quality of the home environment as a mediator in the relation between socioeconomic status and preschool children's vocabulary acquisition.

\section{The Family Investment Model applied to children's vocabulary acquisition}

Differential cognitive child outcomes depending on family socioeconomic status (SES) can be partly explained by genetic factors, reflecting the intergenerational transmission of cognitive abilities (Bartels, Rietveld, Van Baal \& Boomsma, 2002; Dickens, 2005). However, there is also evidence that socialization factors play an important role (Anger \& Heineck, 2010). The Family Investment Model is a mediating model explaining possible pathways between family SES and child developmental outcomes (Conger \& Donellan, 2007). The quality of the home environment has been shown to be an important mediator between the two. According to the Family Investment Model, families with greater wealth and financial prosperity invest more, and more positively, in the physical, emotional, and cognitive development of their children than disadvantaged families. There are only a few Western studies that have examined the full mediation model from SES to family investment to children's language acquisition (Yeung, Linver \& Brooks-Gunn, 2002) and almost none in Latin America. The only study so far conducted in Chile found that higher maternal education 
predicted more maternal cognitive and linguistic stimulation at home, which in turn predicted higher levels of children's receptive vocabulary (Coddington, Mistry \& Bailey, 20I4). Each of the steps of this mediation model are addressed below.

Socioeconomic status and vocabulary acquisition. Socioeconomic status is commonly conceptualized as the social class to which an individual belongs, and is mostly estimated by income, education, and occupation. An individual's life course is determined by social class in manifold ways from the moment of conception to the last breath (Brooks-Gunn, Duncan \& Maritato, I 997). There is convincing evidence, mostly from Western countries, that children's vocabulary acquisition is strongly influenced by family income (Huston et al., 2005) and parental education (Hoff, 2006). In Latin America, higher parental education has been linked to higher vocabulary scores in Chilean and Mexican children (Richman, Miller \& LeVine, I 992; World Bank, 2012).

Socioeconomic status and quality of the home environment. The physical, emotional, and learning environment in which children are raised at home is related to their developmental outcomes. Research in Western samples clearly shows that lower-SES families provide less stimulating home environments (Bradley \& Corwyn, 2002; Bradley, Corwyn, McAdoo \& Garcia Coll, 200 I Prevoo et al., 2014). Low-SES mothers invest less time in mutual play, conversation, and reading activities with their children than middle-SES mothers, partly because they have less material and non-material resources at their disposal and suffer from additional stress due to economic hardship (Bradley \& Corwyn, 2002; Coley, 2002; Hoff-Ginsberg, I 99I). A review reports that in Latin America parents place less emphasis on stimulation and teaching of academic skills than in Western countries (Bradley \& Corwyn, 2005). These cultural practices, coupled with generally poorer living conditions in Latin America, which inter alia manifest in fewer available toys and learning materials in the children's homes, are both likely to negatively affect children's vocabulary acquisition.

Quality of the home environment and vocabulary acquisition. Research in North America and Europe has revealed that children show improved vocabulary acquisition if they grow up in more linguistically and academically stimulating homes, with responsive parents and availability of a variety of age-appropriate learning materials (e.g. Bus et al., I 995; Rodriguez \& Tamis-LeMonda, 20II; Song et al., 20I3). In linguistically and cognitively stimulating homes children are encouraged to explore and to expand their knowledge (Caldwell \& Bradley, 2003). They are exposed to more frequent and more diverse language and are invited to express themselves verbally. Responsive parents converse with their children, attend to their children's speech, praise their children, and may also express their appreciation non-verbally by for instance cuddling, holding, and caressing 
their children. Stimulating homes are also characterized by the availability of learning materials such as books or toys, which may enhance children's cognitive and socio-emotional growth (Isenberg \& Quisenberry, 2002).

\section{The Chilean context}

The following four characteristics of the Chilean context are particularly relevant to the study of preschoolers' language acquisition: SES, ethnicity, single parenthood, and daycare attendance.

Socioeconomic status. UNICEF (Hudson \& Kühner, 20г6) concluded that Chile has the second highest child poverty rate of the developed world after analyzing forty-one OECD (Organization for Economic Cooperation and Development) and European Union countries. Three out of ten children live below the poverty line, which means that $\mathrm{I}, 200,000$ Chilean children are affected. Moreover, the proportion of fifteen-year-olds falling below proficiency level 2 on the PISA tests (Program for International Student Assessment) in reading, math, and science is as high as $24 \cdot 6 \%$ in Chile. This means that a quarter of the adolescent Chilean secondary school students do not understand what they read, cannot solve basic mathematical operations like multiplication or division, and cannot reason about everyday natural occurrences, because they are lacking basic skills and competencies. Acquisition of these skills and competencies starts early in life and language is known to be a fundamental precondition for all academic learning in kindergarten, primary, and secondary school (Forget-Dubois, Dionne, Lemelin, Pérusse, Tremblay \& Boivin, 2009; Harlaar, Hayiou-Thomas, Dale \& Plomin. 2008; NICHD ECCRN, 2005). The apparent deficit of language learning impacts the lives of millions of Chileans not only across the school years, but all across adult life. Seventy-one percent of the Chilean adult population has no post-secondary schooling (CASEN, 20I3), which considerably decreases job opportunities and income, thereby maintaining the cycle of poverty. Early language learning in Chile deserves special research attention, because of the far-reaching societal consequences and the short- and long-term dimension of related problems. The current study aims to examine whether variations in SES within a non-Western low-SES context are related to the quality of the home environment and preschool children's language acquisition.

Ethnicity. Chile is a multi-ethnic society, home to native Americans and descendants of European immigrants. According to single nucleotide polymorphism analysis, a method to map genetic variability, the average Chilean is genetically composed of $42 \%$ native American, 55\% European, and 3\% African ancestry (Eyheramendy, Martinez, Manevy, Vial \& Repetto, 20I5). The indigenous Mapuche people constitute the largest minority group and comprise $9 \%$ of the national population (one and a 
half million people). In the Araucanía region, the stronghold of Mapuche culture, the largest regional Mapuche population $(3 \mathrm{I} \cdot 3 \%)$ and highest regional poverty rates (28\%) of Chile coincide (CASEN, 20I3; INE, 2012. In this particular region, poverty rates are also higher among the Mapuche minority group members compared to Chilean majority group members, which is partially due to lower educational levels, more minimum wage labor, and more unemployment (Cerda, 2009). Nowadays, rural life on ancestral lands or assigned reductions belong to the past for the vast majority of the national Mapuche population (80\%), who exchanged it for life in urban contexts and have hence adopted the dominant Chilean culture, language, religion, and lifestyle (work, housing, health, and education), which makes them largely indistinguishable from majority group members of the same social class (Caniguan, 2012). The ethnic language of the Mapuche is called Mapudungun, and was traditionally a spoken language without written form. Mapudungun was spoken by the Mapuche people before the Law of Obligatory Primary Schooling was adopted in Chile in 1920 (Soto, 2009). This law made attendance at a Western Spanish-speaking school system mandatory for indigenous children, and Mapuche children were punished for speaking their native tongue. Consequently, Spanish has gradually become the dominant language of the Mapuche people over the past century, and Mapudungun is nowadays only spoken with high proficiency by $4 \%$ of Mapuche adolescents between the ages of ten and nineteen years in the south of Chile (Gundermann, Canihuan, Clavería \& Faúndez, 2009). Yet, the broader minority language environment of Mapuche children can still be less conducive to Spanish language acquisition. In the current study, we will take ethnicity into account when examining the predictors of children's vocabulary acquisition.

Single parenthood. Another relevant factor for the study of children's language acquisition in Chile is single parenthood. Twenty percent of all Chilean homes are one-parent households, meaning there is no spouse or partner present (CASEN, 20I I). One-parent households concentrate in the lowest income groups, more than two-thirds fall into the two lowest income categories, which implies that these families are socially vulnerable and are struggling with poverty. In this context, it is important to note that children of single mothers in low-SES environments are at special risk of being linguistically under-stimulated, as their mothers are likely to spend even less time with their children due to higher levels of stress and less social support (Cairney, Boyle, Offord \& Racine, 2003). Heath ( I990) has reported that children of single mothers who have little education and who live in public housing grow up in virtual silence due to lack of maternal speech. Thus, in the current study we will include single parenthood as a covariate in the main analyses. 
Daycare attendance. Quantity of daycare can also impact preschool children's vocabulary acquisition. For children of lower-SES backgrounds, spending more time playing with peers and more involvement with professional caregivers in daycare centers may provide more fertile ground for language development than the immediate family can offer at home, which is in line with the compensatory hypothesis (Desai, Chase-Lansdale \& Michael, I989). In Chile, children spend increasingly more time in daycare, as a consequence of a fast-growing number of working mothers (INE, 20I2) and a considerable expansion of the national public daycare provision. Over the past two decades, nursery school provision quadrupled and kindergarten provision doubled (JUNJI, 2009). Some studies in Chile report beneficial short- and medium-term effects of daycare attendance on language outcomes (Cortázar, 2012; Noboa-Hidalgo \& Urzúa, 20I2), but others report no improvements on vocabulary acquisition (Bucarey, Ugarte \& Urzúa, 20I4; Contreras \& González, 20I5). Such inconclusive results have also been found in Western countries, where sometimes no relationship between daycare attendance and child outcomes are reported (NICHD ECCRN, 2000), whereas others find that a higher quantity of daycare relates to positive cognitive outcomes (e.g. Loeb, Bridges, Bassok, Fuller \& Rumberger, 2007; Luijk et al., 20I5). In the current study, daycare attendance will be included as a covariate in the main analyses.

\section{The current study}

The aim of the current study is to test the Family Investment Model applied to language acquisition in the Latin-American cultural context of Chile, examining parental investment in terms of the quality of the home environment as a mediator in the relation between socioeconomic status and preschool children's vocabulary acquisition. We address the following research questions in a novel bi-ethnic population (Mapuche versus Chilean):

I. What is the association between SES, the quality of the home environment, and preschool children's receptive and expressive vocabulary acquisition in Chile?

2. Is the association between SES and receptive and expressive vocabulary outcome mediated by the quality of the home environment?

We test the following hypotheses:

I. Higher SES is associated with higher quality of the home environment. Higher SES and higher quality of the home environment in turn predict more favorable receptive and expressive vocabulary outcomes among preschool children in Chile. 
2. The association between SES and preschool children's receptive and expressive vocabulary outcome is mediated by the quality of the home environment.

The main analyses include previously described covariates known to relate to early child development, namely ethnicity, parental caregiver status, and quantity of daycare attendance.

\section{METHOD}

\section{Participants}

The current study draws on an existing sample which was recruited at the baseline of the longitudinal Magellan-Leiden Childcare Study (Cárcamo, Vermeer, van der Veer \& van IJzendoorn, 20I5), which started in February 2012 (Time I) with I I 0 mothers of 6-month-old infants born in 20II. The initial sample was drawn from three public health centers and records of nineteen public daycare centers in the Araucanía region and on Chiloé Island (Lake region) in Chile. Nine months later at Time 2, when the children were $\mathbf{5}_{5}$ months old, the initial number of participants had decreased to 95 due to sample attrition. At Time 3 (January 2015), when the children were 42 months old, sixteen additional mother-child dyads declined participation for various reasons (mostly due to lack of time). Two of the remaining seventy-nine dyads, who gave their written consent for the Time 3 measurement, were excluded due to missing outcome variables. This resulted in a current sample of seventy-seven motherchild-dyads (8I\% of the Time 2 sample and $70 \%$ of initial sample). Participating dyads are from low- to lower-middle-class ethnic majority Chilean $(n=45)$ and ethnic minority indigenous Mapuche $(n=32)$ background. Mean household income per capita was $\mathrm{I} \cdot 74(\mathrm{SD}=\mathrm{I} \cdot \mathrm{I} 4)$ on a 5-point scale according to national quintile distribution (for details about SES assessment see 'Measures' subsection). Mothers' educational level $(\mathrm{M}=2 \cdot \mathrm{I} 7, \mathrm{SD}=0.83$, on a 4 -point scale) was distributed as follows: $18 \cdot 2 \%$ either only completed primary school or did not complete secondary school; $55.8 \%$ completed secondary school; i $6 \cdot 9 \%$ completed vocational school; and $9 \cdot 1 \%$ completed university studies. Mean age of mothers was 28.95 years and almost all primary caregivers were mothers, with the exception of one father. Forty-four percent of the children were raised by a single parent and $58 \%$ are boys. See Table I for descriptive statistics of childcare, vocabulary acquisition, and family characteristics.

\section{Procedure}

Ethical approval was obtained by the Ethical Committee Board of Leiden University (the Netherlands). Data of the present time-point of our 
TAB LE I . Descriptive statistics of childcare, vocabulary acquisition, and family characteristics

\begin{tabular}{|c|c|c|c|}
\hline & & \multicolumn{2}{|c|}{ Total $(\mathrm{N}=77)$} \\
\hline & & M & $\mathrm{SD}$ \\
\hline \multicolumn{4}{|c|}{ Childcare and development variables } \\
\hline \multicolumn{2}{|c|}{ HOME quality (percentage $T_{I}-T_{3}$ ) } & $73 \cdot 19$ & $6 \cdot 85$ \\
\hline \multicolumn{2}{|c|}{ Receptive vocabulary } & $20 \cdot 21$ & II. 66 \\
\hline \multicolumn{2}{|c|}{ Expressive vocabulary } & 35.91 & I2.68 \\
\hline \multicolumn{4}{|c|}{ Family characteristics } \\
\hline \multicolumn{2}{|c|}{ Maternal age (years) } & $28 \cdot 95$ & $7 \cdot 7 \mathrm{I}$ \\
\hline \multicolumn{2}{|c|}{ Number of children } & $\mathrm{I} \cdot 77$ & 0.87 \\
\hline \multicolumn{2}{|c|}{ Child age (months) } & $4 \mathrm{I} \cdot 89$ & $\mathrm{I} \cdot 25$ \\
\hline \multicolumn{2}{|c|}{ Quantity of daycare $(6-42 \mathrm{~m})$} & $34 \cdot 76$ & $28 \cdot 78$ \\
\hline & & $\mathrm{N}$ & $\%$ \\
\hline \multirow[t]{2}{*}{ Ethnicity } & Mapuche & 32 & $4 \mathrm{I} \cdot 56$ \\
\hline & Chilean & 45 & $58 \cdot 44$ \\
\hline \multirow[t]{2}{*}{ SES } & Low & 36 & $46 \cdot 75$ \\
\hline & Lower-middle & $4 \mathrm{I}$ & $53 \cdot 25$ \\
\hline \multirow[t]{2}{*}{ Child gender } & Male & 45 & $58 \cdot 4$ \\
\hline & Female & 32 & $4 \mathrm{I} \cdot 6$ \\
\hline \multirow[t]{2}{*}{ Caregiver status } & One parent & 34 & $44 \cdot 2$ \\
\hline & Two parents & 43 & $55 \cdot 8$ \\
\hline
\end{tabular}

longitudinal study were collected by six trained female undergraduate psychology students of the Autónoma University Temuco, Chile. Participating dyads received three visits from December 2014 to February 2015 (Time 3), including a brief pre-visit of approximately 30 minutes and two home visits of approximately 90 minutes each. During the pre-visit the primary caregiver was informed about the subsequent data collection and invited to continue participating, after which the informed consent form was signed. During the Time 3 home visits the quality of the home environment was observed, children's receptive and expressive vocabulary was assessed, and mothers filled out a questionnaire about demographic data (education, employment, income), family and household composition, the child's health and daycare attendance, and major life events. Tests were administered to all children according to a standardized sequential order and all testing was either audio- or video-recorded to enable decisions on scoring afterwards in case of ambiguous answers. The participants received a Io,000 CLP (Chilean Pesos; US\$I6) voucher of a local supermarket or convenience store as remuneration for their collaboration. 


\section{Measures}

Socioeconomic status. SES was computed as a composite of maternal education and per capita income level. The level of maternal education was self-reported at Time 3 on a $\mathrm{I}-4$-point scale $(\mathrm{I}=$ incomplete primary or secondary school; 2 = secondary school completed; 3 = vocational education; $4=$ university studies). Four mothers did not report their educational level. In these cases the missing data were replaced with maternal educational level at Time 2 as best estimate. At Time 2, mothers were asked in a questionnaire to indicate their total gross monthly household income in Chilean Pesos divided by the number of household members. This resulted in six per capita income answer categories: no income (I), less than 6I,9I I Chilean Pesos (US\$II4) (2), between 6r,9 I2 and I05,907 CLP (US\$195) (3), between 105,908 and I67,879 CLP (US\$3 10 ) (4), between I67,880 and 300,869 CLP (UD\$556) (5), and more than 300,870 CLP (6). The socioeconomic categorization is based on the five quintiles of the Chilean Ministry of Social Development (MIDESO, n.d.). The first quintile reflects the most socioeconomically vulnerable members of society $(20 \%$ of the national population), whereas the fifth quintile encompasses the most affluent Chileans. The maternal education and per capita income level were combined into one global indicator of SES by summing the standardized scores of both measures. We then dichotomized this variable due to limited variance of the income and education variables $(82 \%$ of the sample had a monthly per capita income below US\$200, and $75 \%$ of the mothers had no tertiary education). A median split was performed in order to group the participating families in low and lower-middle SES, resulting in two groups (low SES, $\mathrm{N}=36$; lower-middle SES, $\mathrm{N}=4 \mathrm{I}$ ).

Quality of home environment. The Infant/Toddler Home Observation for Measurement of the Environment (IT-HOME; Caldwell \& Bradley, 2003) was used at Time I and Time 2 when children were 6 and 15 months old, respectively (for details see Cárcamo et al., 2015). The Early Childhood Home Observation for Measurement of the Environment (EC-HOME; Caldwell \& Bradley, 2003) was used to measure quality and quantity of stimulation and support available to a child in the home environment at Time 3. The IT-HOME and EC-HOME are both comprised of two parts: an observation of the home environment followed by a semi-structured interview with the primary caregiver of approximately 30 minutes each. In one case the primary caregiver was the child's father (single parent) and in one case the interview was conducted with the great aunt instead of the mother. The IT-Home consists of forty-five binary choice items $(\mathrm{I}=$ positive, $\circ=$ negative) grouped in six subscales (responsivity, acceptance, organization, learning materials, involvement, variety), and the EC-Home consists of fifty-five binary choice items ( $\mathrm{I}=$ positive, $\mathrm{o}=$ negative $)$ grouped in eight subscales (learning materials, language stimulation, physical 
environment, responsivity, academic stimulation, modeling, variety, and acceptance). The HOME has been administered in many countries around the world, including Chile, and its validity for minority and low-SES groups has been well established (Bradley et al., 200ı; Bustos Correa, Herrera \& Mathiesen, 200I; Cárcamo et al., 20I5). The EC-HOME assessment was performed by the research assistants after an extensive training period (studying the manual, discussing items, video-scoring, and a pilot home visit). Observers achieved an average of $94 \%$ agreement with expert scoring when inter-rater reliability was assessed. Internal consistency of the instrument was high, with a Cronbach's alpha of .8I. An accumulated HOME score was computed, indicating the overall quality of the home environment across all three time-points by calculating mean percentage scores. All three HOME measurements were significantly correlated with each other; Pearson correlations ranged from .26 to .40.

Receptive vocabulary. The Spanish adaptation of the Peabody Picture Vocabulary Test (PPVT) was used (TVIP-Test de Vocabulario en Imágenes Peabody) to assess children's receptive vocabulary, because all participating children spoke Spanish as their first language (Dunn, Padilla, Lugo \& Dunn, I986). During test administration, the child is shown one of the 125 black and white test plates at a time, and after the research assistant names one of the four objects on the test plate the child has to point to the correct picture. Just as with the PPVT, the TVIP has proven to be a reliable and valid instrument for receptive vocabulary assessment over the years (ACYF, 2003; Piñeiro, Manzano, Inguanzo, Reigosa, Morales \& Fernández, 2000). In the current study the split-half (odd/even) sample reliability was $>\cdot 95$. There was one missing score due to the child's refusal to do the test and one child did not entirely finish the TVIP due to experimenter error. Each child's missing score was estimated based on the particular child's percentile score on the Expressive One Word Picture Vocabulary Test (EOWPVT-4). The final score is the number of correct responses between base and ceiling items.

Expressive vocabulary. The Expressive One Word Picture Vocabulary Test-Spanish Bilingual Edition (EOWPV'T-4-SBE) measures children's ability to generate words (Nancy, 2013). The child is shown one of the 80 color pictures at a time, and after a prompting question by the research assistant has to generate the word that best describes the object, concept, or action. A Cronbach's alpha of .95 indicates high internal consistency of the EOWPVT-4-SBE for Hispanic children aged three and four in the US (Nancy, 20I3). In the current study the split-half (odd/even) sample reliability was $>\cdot 94$. One very low early suspension score (child was unmotivated) was replaced by an estimate based on the same child's percentile score on the TVIP. The final score is the number of correct responses between base and ceiling items. 


\section{Background variables}

Ethnicity. The ethnicity of the participating mother-child dyads was determined by self-report (Cárcamo et al., 20 I5). Dyads were defined as Mapuche when mothers stated that their children grow up in a Mapuche family.

Parental caregiver status. The caregiver status of the participating parents was determined by self-report. Children were defined as growing up in one-parent families when it was reported that the father (or in one case mother) was not living in the same household as the child.

Quantity of daycare. Directors of the daycare centers in the Araucanía region and on Chiloé Island and collaborating JUNJI (National Council of Daycare Centers) and INTEGRA (National Network of Nursery Schools and Kindergartens) staff were contacted in order to obtain the children's daycare attendance of the previous three years (2012-20I4). They were asked to report how many days per monthly working days the participating children attended daycare. These numbers were transformed into a total percentage of each child's daycare attendance between 6 and 42 months. For two children, the daycare centers could not provide the information for the year 2012. In these cases the child's daycare attendance was estimated based on the child's daycare attendance percentile scores for the year 20I3.

\section{Analysis plan}

Language measures, HOME global quality, daycare attendance, maternal age, maternal education, and per capita income were inspected for outliers defined as values with SD greater than 3.29 above the mean (Tabachnick \& Fidell, I 996). No outliers were found. All variables were normally distributed with the exception of quantity of daycare, which can be expected as not all children attended daycare. Pearson correlation coefficients were computed to inspect the bivariate associations between all variables.

As primary analyses, hierarchical multiple regression analyses (HMR) were conducted to test whether receptive and expressive child vocabulary at $3 \frac{1 / 2}{2}$ years varied as a function of SES and the quality of home environment, controlling for ethnicity, parental caregiver status, and quantity of daycare. The models included the following variables: SES (o=low; I = lower-middle), home quality (percentage across Time I, Time 2, and Time 3), ethnicity (o=Chilean majority; $\mathrm{I}=$ Mapuche minority), parental caregiver status ( $\mathrm{o}=$ one-parent, $\mathrm{I}=$ two-parents $)$, and quantity of daycare (percentage of total daycare attendance from 6-42 months). 
Mediation analyses were performed to examine whether SES had an indirect effect on receptive and expressive vocabulary through the quality of the home environment. The Preacher and Hayes method to test mediation was applied using the macro package for SPSS available online, which allows for multiple mediators. This test is not based on large-sample theory, meaning it can be applied to small samples with more confidence. This method adopts the bootstrapping approach which, unlike the Sobel test, respects the non-normality of the sampling distribution of the indirect effect (Preacher \& Hayes, 2008). This approach bootstraps the sampling distribution of the indirect effect and derives a confidence interval with the empirically derived bootstrapped sampling distribution (Preacher \& Hayes, 2004). The bootstrapping is accomplished by taking a large number of samples of the original sample from the data and computing the indirect effect in each sample, which is also called sampling with replacement. Five thousand bootstrap resamples were generated and the significance of the indirect effect was tested using bias-corrected bootstrap $95 \%$ confidence intervals.

\section{RESULTS}

\section{Sample inspection}

We compared the remaining sample to the dropouts. An independent $t$-test indicated that the dropouts $(n=33 ; \mathrm{M}=23.2 \mathrm{I} ; \mathrm{SD}=5.67)$ were significantly different from the current participants $(n=77 ; \mathrm{M}=26.30 ; \mathrm{SD}=7.67)$ in terms of maternal age, with relatively more younger mothers among the dropouts than among the remaining mothers $\left[t(1 \circ 8)=2 \cdot 08, p<.0_{5}\right]$. This was partly due to the tendency of teenage mothers to be unavailable for participation at Time 3. A chi-square test revealed another significant difference between the dropouts and current participants on SES $\left[\chi^{2}(\mathrm{I}, N=\mathrm{I} \mathrm{IO})=28.0 \mathrm{I}, \quad p<.0 \mathrm{I}\right]$. All of the 33 families that discontinued participating in this study were from low-SES backgrounds. No differences emerged between the dropouts and the current sample on child gender $\left[\chi^{2}(\mathrm{I}, N=\mathrm{I}\right.$ I0 $\left.)=0.14, p=.7 \mathrm{I}\right]$, ethnicity $\left[\chi^{2}(\mathrm{I}, N=\right.$ I I0 $)=$ $\mathrm{I} \cdot 24, p=\cdot 27]$, and marital status $\left[\chi^{2}\left(\mathrm{I}, N=\mathrm{I}_{\mathrm{I}} \mathrm{o}\right)=0.26, p=.6 \mathrm{I}\right]$.

We further compared our sample to the large-scale nationally representative sample of the Longitudinal Survey of Early Childhood (ELPI-Encuesta Longitudinal de la Primera Infancia) on overlapping measures (Cárcamo et al., 20I5). We found that the mean per capita income in our sample was below the mean national per capita income per month. Also, participating mothers had less education. This is consistent with our characterization of the current sample as 'low-SES'. The HOME results of our study $(\mathrm{M}=73.13 \%, \mathrm{SD}=6.85)$ were in the typical range compared to low-SES participants of the ELPI sample $(\mathrm{M}=72 \cdot 47 \%$, 
$\mathrm{SD}=4 \cdot 44)$. The TVIP results of our study $(\mathrm{M}=20 \cdot 2$ I $\mathrm{SD}=\mathrm{I}$ I 66$)$ were also in the typical range compared to low-SES participants of the ELPI sample $\left(\mathrm{M}=\mathrm{I}_{7} \cdot 04, \mathrm{SD}=\mathrm{I} 2 \cdot 69\right)$.

\section{Bivariate associations between predictors and outcomes}

Pearson correlations were calculated for all variables (see Table 2). Receptive and expressive vocabulary were significantly associated $(r(75)=.6 \mathrm{I}, p<\cdot 0 \mathrm{I})$. Home quality significantly correlated with receptive $(r(75)=\cdot 28, p<\cdot 05)$ and expressive vocabulary $(r(75)=.30, p<\cdot 0 \mathrm{I})$, and with $\operatorname{SES}(r(75)=.29$, $p<\cdot 0 \mathrm{I})$. SES was furthermore significantly positively associated with expressive vocabulary $(r(75)=.23, p<\cdot 05)$. All other correlations were non-significant.

\section{Predicting vocabulary acquisition}

Two three-stage hierarchical multiple regression analyses were conducted with receptive and expressive vocabulary as outcome variables, respectively. Ethnicity, parental caregiver status, and quantity of daycare attendance were entered at stage one of the regression to control for demographic background variables. SES was entered at stage two, and the quality of the home environment at stage three. The variables were entered in this order according to the Family Investment Model. At stage one the demographic background variables neither significantly predicted receptive vocabulary $[F(3,73)=\mathrm{I} \cdot 57, p=\cdot 20]$, nor expressive vocabulary $\left[F(3,73)=I_{1} I_{3}, p=\cdot 34\right]$. At stage two, SES did not contribute significantly to the prediction of receptive vocabulary $\left[F(4,72)=I_{5} \cdot 54, p=\cdot 20\right]$ or expressive vocabulary $\left[F(4,72)={ }_{1} \cdot 79, p=\cdot 06\right]$. Including quality of the home environment to the model at stage three explained an additional $6 \%$ of the variance in receptive and expressive vocabulary. The quality of home environment was a marginally significant predictor of receptive vocabulary $[F(5,7 \mathrm{I})=2 \cdot 25, p=.06]$ and a significant predictor of expressive vocabulary $[F(5,7 \mathrm{I})=2.55, p<.05]$, above and beyond SES and the demographic variables. Together the five predictors accounted for $14 \%$ of the variance in receptive vocabulary and for ${ }_{5} \%$ of the variance in expressive vocabulary. Table 3 shows the results of the hierarchical multiple regression analyses.

\section{Testing the mediation models}

Next, we tested whether the quality of the home environment fully or partially mediated the relation between SES and receptive and expressive vocabulary acquisition, respectively. As Figures Ia and Ib illustrate, the standardized regression coefficient between SES and quality of home environment was significant, as was the standardized regression coefficient 
TABLE 2. Correlations between receptive and expressive vocabulary, quality of home environment, quantity of daycare attendance, and family characteristics $(N=77)$

\begin{tabular}{|c|c|c|c|c|c|c|c|c|}
\hline & & I & 2 & 3 & 4 & 5 & 6 & 7 \\
\hline I & Receptive vocabulary & - & & & & & & \\
\hline 2 & Expressive vocabulary & $0.6 \mathrm{I} * *$ & - & & & & & \\
\hline 3 & $\begin{array}{l}\text { HOME quality } \\
\left(\text { percentage } \mathrm{T}_{\mathrm{I}}-\mathrm{T}_{3}\right)\end{array}$ & $0.28 *$ & $0.30 * *$ & - & & & & \\
\hline 4 & Ethnicity $^{\mathrm{a}}$ & -0.17 & -0.20 & 0.00 & - & & & \\
\hline 5 & Socioeconomic status & 0.14 & $0.23^{*}$ & $0.29 * *$ & $-0 \cdot I_{I}$ & - & & \\
\hline 6 & $\begin{array}{l}\text { Parental caregiver } \\
\text { status }{ }^{b}\end{array}$ & -0.14 & -0.03 & -0.09 & $-O \cdot I I$ & 0.01 & - & \\
\hline 7 & $\begin{array}{l}\text { Quantity of daycare } \\
(6-42 \mathrm{~m})\end{array}$ & -0.05 & -0.03 & 0.05 & 0.04 & O. I I & -0.17 & - \\
\hline
\end{tabular}

NOTEs: ${ }^{a} \mathrm{o}=$ Chilean majority, $\mathrm{I}=$ Mapuche minority.

${ }^{\mathrm{b}} \mathrm{o}=$ one parent, $\mathrm{I}=$ two parents; $* x<.05$, ** $p<.0 \mathrm{I}$.

TABLE 3. Hierarchical regression analyses predicting receptive and expressive vocabulary from quality of home environment $(N=77)$

\begin{tabular}{|c|c|c|c|c|c|c|}
\hline \multirow[b]{5}{*}{ Predictors } & \multicolumn{3}{|c|}{ Model I } & \multicolumn{3}{|c|}{ Model 2} \\
\hline & \multicolumn{3}{|c|}{ Receptive vocabulary ${ }^{a}$} & \multicolumn{3}{|c|}{ Expressive vocabulary $^{\mathrm{b}}$} \\
\hline & $R^{2}=.06$ & $R^{2}=.08$ & $R^{2}=\cdot I_{4}$ & $R^{2}=.04$ & $R^{2}=.09$ & $R^{2}=\cdot I_{5}$ \\
\hline & $p=\cdot 20$ & $p=\cdot 20$ & $p=.06$ & $p=\cdot 34$ & $p=\cdot I_{4}$ & $p=.04$ \\
\hline & $\beta$ & $\beta$ & $\beta$ & $\beta$ & $\beta$ & $\beta$ \\
\hline Ethnicity & $-0 \cdot 19$ & -0.18 & $-0 \cdot 18$ & $-0.2 \mathrm{I}$ & $-0 \cdot 18$ & $-0 \cdot 19$ \\
\hline Parental caregiver status & -0.17 & -0.17 & $-0 . I_{5}$ & -0.05 & -0.06 & -0.03 \\
\hline Quantity of daycare $(6-42 \mathrm{~m})$ & -0.08 & -0.09 & -0.09 & -0.03 & -0.06 & -0.06 \\
\hline Socioeconomic status & & 0.14 & 0.06 & & 0.22 & 0.14 \\
\hline $\begin{array}{l}\text { Home quality } \\
\left(\text { percentage } \mathrm{T}_{1}-\mathrm{T}_{3}\right)\end{array}$ & & & $0.25 *$ & & & $0.26^{*}$ \\
\hline
\end{tabular}

Notes: ${ }^{a}$ Test de Vocabulario en Imágenes $=$ Spanish version of Peabody Picture Vocabulary Test (Dunn, Padilla, Lugo, \& Dunn, I 986);

${ }^{\mathrm{b}}$ Expressive One-Word Picture Vocabulary Test - four - Spanish Bilingual Edition (Nancy, $2013) ; * p<.05$.

between quality of home environment and both receptive and expressive vocabulary acquisition. A simple association between SES and vocabulary acquisition is not required in order to test mediation hypotheses (Hayes, 2009). We examined the significance of this indirect effect (the indirect effect of $X$ on $Y$ is defined as the product of the $X \rightarrow M$ path and the $M \rightarrow$ $Y$ path) using the previously described bootstrapping procedures by 
Preacher and Hayes (2004, 2008). We found that the direct relationship between SES and both receptive and expressive vocabulary diminished when the quality of the home environment was included in the model, indicating partial mediation. The first mediation analysis (see Figure ra) revealed that the indirect effect from SES to receptive vocabulary through quality of home environment was significant $[\beta=.08, S E=0.05,95 \% \mathrm{CI}$, $\mathrm{BCaCI}(0.0 \mathrm{I}, 0.2 \mathrm{I})]$. The bootstrapped standardized indirect effect was .08 , and the $95 \%$ Bias Corrected and Accelerated Confidence Interval ranged from $0.0 \mathrm{I}$ to $0.2 \mathrm{I}$. The lower and upper limit of the Confidence Interval did not pass through zero, which means that the indirect effect is statistically significant. The mediator thus accounted for roughly half of the total effect of SES on receptive vocabulary acquisition. The second mediation analysis (see Figure $\mathrm{rb}$ ) demonstrated that the indirect effect from SES to expressive vocabulary through quality of home environment was significant as well $[\beta=.08, S E=0.04,95 \% \mathrm{CI}, \mathrm{BCaCI}(0.0 \mathrm{I}, 0 . \mathrm{I} 8)]$, and accounted for roughly one-third of the total effect between SES and expressive vocabulary acquisition.

\section{DISCUSSION}

Our findings advance the understanding of how SES and the quality of the home environment relate to preschool children's vocabulary acquisition in a non-Western context. We investigated the associations between receptive and expressive vocabulary, quality of home environment, SES, ethnicity, parental caregiver status, and quantity of daycare. We found associations between the quality of the home environment, SES, and vocabulary acquisition. In contrast, ethnicity, parental caregiver status, and quantity of daycare did not explain variations in vocabulary acquisition. As expected, participating preschool children in Chile with higher-quality home environments showed higher receptive and expressive vocabulary scores. The effect of the quality of home environment on vocabulary development remained above and beyond the effects of ethnicity, SES, parental caregiver status, and quantity of daycare attendance. Previous research has shown a positive relation between quality of home environment and language outcomes for children in Western countries (Bus et al., I995; Rodriguez \& Tamis-LeMonda, 20 I I). We are the first to find similar results in a bi-ethnic low-SES sample in a novel Latin American context, consisting of indigenous Mapuche minority and Chilean majority families in Chile. Our findings support the universal effects assumption that entails cross-cultural similarities in developmental processes despite mean-level differences, and suggests that the quality of home environment matters for children's vocabulary acquisition in Chile, as it does for children in Western countries. 
(a)

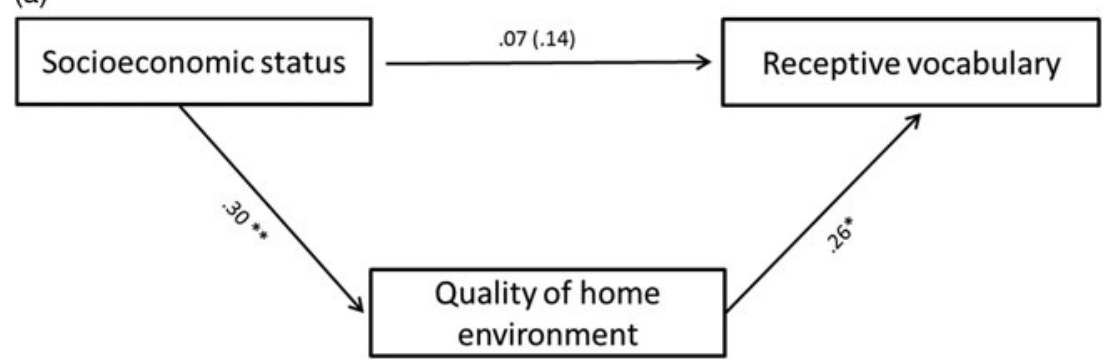

Fig. Ia. The mediating role of quality of home environment in the relation between socioeconomic status and receptive vocabulary $(N=77)$. Numbers represent standardized coefficients $(\beta)$. The coefficient prior to the parentheses depicts the association between SES and receptive vocabulary, controlling for quality of home environment, whereas the coefficient within the parentheses reflects the total effect (direct effect + indirect effect) without controlling for the mediator. ${ }^{*} p<.05$; $* * 0.0 \mathrm{I}$.

(b)

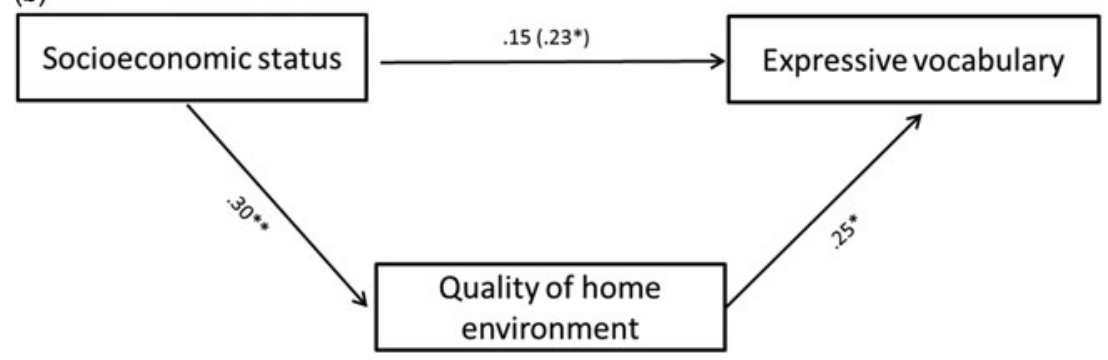

Fig. Ib. The mediating role of quality of home environment in the relation between socioeconomic status and expressive vocabulary $(N=77)$. Numbers represent standardized coefficients $(\beta)$. The coefficient within the parentheses reflects the total effect (direct effect + indirect effect) without controlling for the mediator, and the coefficient prior to the parentheses depicts the association between SES and expressive vocabulary, controlling for quality of home environment. $* p<.05 ; * *<<.0 \mathrm{I}$.

We also investigated whether quality of the home environment mediated the relation between SES and receptive and expressive vocabulary. As expected, we found that the association between SES and both receptive and expressive vocabulary was partially mediated by quality of the home environment. Low-SES mothers in our sample provided less enriching home environments to their children (e.g. less cognitive and linguistic stimulation, less learning materials), which resulted in lower vocabulary outcomes. Our findings thus support the Family Investment Model (Conger \& Donnellan, 2007), which highlights the importance of financial, 
educational, and occupational resources and parental investments in their children as pathways for child development. According to our results, SES indirectly affects children's language learning outcomes through the provision of an adequate language learning environment at home. The mediating role of the quality of the home environment in the relation between SES and vocabulary acquisition is in line with prior research conducted in Chile (Coddington et al., 20I4). If replicated, the home environment can open up crucial avenues for intervention by offering more linguistic opportunities for low-SES children.

The included covariates ethnicity, parental caregiver status, and daycare attendance did not predict receptive or expressive vocabulary. Mapuche minority children and Chilean majority children did not differ in their receptive and expressive vocabulary. The absence of these differences seems consistent with prior findings indicating that the majority of the Mapuche are largely indistinguishable from their Chilean compatriots due to adaptation to the dominant culture and urbanized life style (Caniguan, 2012). In our sample, one-parent caregiving was not significantly negatively associated with children's vocabulary acquisition as the literature-mostly based on Western samples-suggests. This could be explained by the fact that, contrary to the situation in Western countries, single mothers in Chile rarely live on their own. Multigenerational households are very common, especially among low-SES groups in which immediate and/or extended family members live collectively under one roof. These circumstances may naturally compensate for the absence of non-resident fathers in terms of linguistic stimulation. Likewise, quantity of daycare attendance between 6 and 42 months did not contribute to preschool children's vocabulary acquisition. The large scale and nationally representative sample of the ELPI study in Chile did not find significant associations either between daycare attendance and receptive language performance (Contreras \& González, 20I5). Possibly, the quality of daycare may be more important than the quantity of daycare when it comes to explaining individual differences in vocabulary acquisition of low-SES children, as has been shown in several international large-scale studies (Love et al., 2003; NICHD ECCRN, 2002).

Strong points of the study include the so far under-studied Latin-American cultural context of both indigenous Mapuche ethnic minority families and ethnic majority families in Chile, in combination with the longitudinal design, the use of observational and performance measures, and the inclusion of both receptive and expressive language outcomes. There are also some limitations. First, the indigenous sample might not be representative of the general Mapuche population in Chile that also includes more isolated communities of Mapuche in remote rural areas who are still more affiliated with their traditions and native language. 
Second, $30 \%$ of the original sample, which was recruited at the initiation of the longitudinal study in $20 \mathrm{I} 2$, was lost, and drop-out mothers were younger and from the lowest SES level. Finally, the quality of the daycare environment was not included in this study, which limits our understanding of how daycare programs impact children's linguistic development.

In agreement with the Family Investment Model, our findings underline the crucial role of family processes in predicting individual differences in preschool children's vocabulary acquisition (Conger \& Donnellan, 2007). The fact that these results were obtained by testing the full mediation model in a non-Western bi-ethnic sample suggests that these family processes might be universal. Theories do need to be mindful of culture-specific processes, however, such as the wider social networks that play a larger role in non-Western communities than in Western countries, and thus might mitigate the effects of risk factors such as single parenthood. Further, the current study provides evidence that theoretical models of the negative influence of socioeconomic adversity also applies to variations WITHIN low-SES populations, suggesting that even marginal increments in SES can benefit family functioning and child language acquisition. Inasmuch as family SES is difficult to modify, our study points to family processes as an important pathway for interventions directed at the improvement of linguistic development in low-SES children. Indeed, a review of home interventions in developing countries revealed that improving young children's cognitive stimulation and learning opportunities has a significant impact on their cognitive functioning (Walker et al., 2007). Such interventions do need to be analyzed carefully, however, to uncover potential cultural factors that need to be taken into account. In conclusion, the current study confirms existing theoretical frameworks regarding family processes and child development, and builds on empirical work pointing towards parents as crucial agents in attempts to improve child language acquisition, not only in Western countries, but also in the cultural context of Latin America. Undoubtedly, more research is needed in non-Western populations to further explore the universality of the mechanisms behind vocabulary acquisition, particularly in at-risk populations.

\section{REFERENCES}

ACYF (Administration for Children, Youth \& Families) (2003). Head Start FACES (2000): a whole child perspective on program performance fourth progress report. Washington, DC: ACYF. Online: <http://files.eric.ed.gov/fulltext/ED478791.pdf>.

Anger, S. \& Heineck, G. (2010). Do smart parents raise smart children? The intergenerational transmission of cognitive abilities. Fournal of Population Economics 23(3), I 105-32. 
Bartels, M., Rietveld, M. J., Van Baal, G. C. M. \& Boomsma, D. I. (2002). Genetic and environmental influences on the development of intelligence. Behavior Genetics 32(4), 237-49.

Bornstein, M. H. (I 995). Form and function: implications for studies of culture and human development. Culture $\Xi$ Psychology I, I $23-37$.

Bornstein, M. H., Putnick, D. L., Lansford, J. E., Deater-Deckard, K. \& Bradley, R. H. (2015). A developmental analysis of caregiving modalities across infancy in 38 low-and middle-income countries. Child Development 86, I 57 I-87.

Bradley, R. H. \& Corwyn, R. F. (2002). Socioeconomic status and child development. Annual Review of Psychology 53, 37 I-99.

Bradley, R. H. \& Corwyn, R. F. (2005). Caring for children around the world: a view from HOME. International Fournal of Behavioral Development 29, 468-78.

Bradley, R. H., Corwyn, R. F., McAdoo, H. P. \& Garcia Coll, C. (200I). The home environments of children in the United States part I: variations by age, ethnicity, and poverty status. Child Development 72, i $844-67$.

Brooks-Gunn, J., Duncan, G. J. \& Maritato, N. (I997). Poor families, poor outcomes: the well-being of children and youth. In G. J. Duncan \& J. Brooks-Gunn (eds), Consequences of growing up poor, I-I7. New York: Russell Sage Foundation.

Bucarey, A., Ugarte, G. \& Urzúa, S. (2014). El efecto de la educación preescolar en chile. [The effect of preschool education in Chile]. Technical report. Online: <http://clientes.hugoo. com/temp/99/banco/Impacto_Educ_Parvularia_SIMCE_marzo20 I 4.pdf $>$.

Bus, A. G., van IJzendoorn, M. H. \& Pellegrini, A. D. (I995). Joint book reading makes for success in learning to read: a meta-analysis on intergenerational transmission of literacy. Review of Educational Research 65, I-2 I

Bustos Correa, C., Herrera, M. O. \& Mathiesen, M. E. (200I). Calidad del ambiente del hogar: Inventario HOME como un instrumento de medición [Quality of the home environment: the HOME inventory as a measurement instrument]. Estudios Pedagógicos 27, 7-22.

Cairney, J., Boyle, M., Offord, D. R. \& Racine, Y. (2003). Stress, social support and depression in single and married mothers. Social Psychiatry and Psychiatric Epidemiology 38, 442-9.

Caldwell, B. M. \& Bradley, R. H. (2003). Home observation for measurement of the environment: administration manual. Little Rock, AR: University of Arkansas.

Caniguan, N. (2012). Infancia mapuche y migración en el Budi [Mapuche infancy and migration in the Budi]. Revista Iberoamericana sobre Niñez y Fuventud en Lucha por sus Derechos 4, I 35-4I.

Cárcamo, R. A., Vermeer, H. J., van der Veer, R. \& van IJzendoorn, M. H. (20 I 5). Childcare in Mapuche and non-Mapuche families in Chile: the importance of socioeconomic inequality. Fournal of Child and Family Studies 24, 2668-79.

CASEN (20II). Ministry of Social Development: Survey of national socioeconomic characterization. Online: <http://observatorio.ministeriodesarrollosocial.gob.cl/casen/ basededatos_historico.php>.

CASEN (2013). Ministry of Social Development: The situation of poverty in Chile. Online: <http://observatorio.ministeriodesarrollosocial.gob.cl/documentos/Casen20r3_Situacion_ Pobreza_Chile.pdf>.

Cerda, R. (2009). Situación socioeconómica reciente de los mapuches en la región de La Araucanía [Recent socioeconomic situation of the Mapuche in the Araucania region]. Estudios Públicos 113, 27-108.

Coddington, C. H., Mistry, R. S. \& Bailey, A. L. (2014). Socioeconomic status and receptive vocabulary development: replication of the parental investment model with Chilean preschoolers and their families. Early Childhood Research Quarterly 29, 538-49.

Coley, R. J. (2002). An uneven start: indicators of inequality in school readiness. Policy information report. Princeton, NJ: Educational Testing Service. Online: <http://www.ets. org/research/policy_research_reports/publications/report/2002/cikm>. 
Conger, R. D. \& Donnellan, M. B. (2007). An interactionist perspective on the socioeconomic context of human development. Annual Review of Psychology 58, I 75-99.

Contreras, D. \& González, S. (2015). Determinants of early child development in Chile: health, cognitive development and demographic factors. International fournal of Educational Development 4o, 2 I 7-30.

Cortázar, A. (2012). Long-term effects of early childhood education on academic achievement in Chile. Doctoral dissertation, Teachers College, Columbia University. Available from ProQuest Dissertations and Theses database (UMI No. 3492908).

Desai, S., Chase-Lansdale, P. L. \& Michael, R. T. (I989). Mother or market? Effects of maternal employment on the intellectual ability of 4-year-old children. Demography 26, $545^{-6} \mathrm{I}$.

Dickens, W. T. (2005). Genetic differences and school readiness. Future of Children $\mathbf{1 5}$ (I), 55-69.

Dunn, L. M., Padilla, E. R., Lugo, D. E. \& Dunn, L. M. ( I 986). Manual del examinador para el Test de Vocabulario en Imágenes Peabody [The experimenter's manual for the Peabody Picture Vocabulary Test]. Minneapolis, MN: Pearson Assessment.

Eyheramendy, S., Martinez, F. I., Manevy, F., Vial, C. \& Repetto, G. M. (2015). Genetic structure characterization of Chileans reflects historical immigration patterns. Nature Communications 6, I-IO.

Forget-Dubois, N., Dionne, G., Lemelin, J. P., Pérusse, D., Tremblay, R. E. \& Boivin, M. (2009). Early child language mediates the relation between home environment and school readiness. Child Development 8o(3), 736-49.

Gundermann, H., Canihuan, J., Clavería, A. \& Faúndez, C. (2009). Permanencia y desplazamiento, hipótesis acerca de la vitalidad del mapuzugun [Permanence and displacement hypothesis about the vitality of Mapuzungun]. RLA. Revista de Lingüistica Teórica y Aplicada 47, 37-60.

Harlaar, N., Hayiou-Thomas, M. E., Dale, P. S. \& Plomin, R. (2008). Why do preschool language abilities correlate with later reading? A twin study. Fournal of Speech, Language, and Hearing Research 5I, 688-705.

Hayes, A. F. (2009). Beyond Baron and Kenny: statistical mediation analysis in the new millennium. Communication Monographs 76, 408-20.

Heath, S. B. (1990). The children of Trackton's children: spoken and written language in social change. Cambridge: Cambridge University Press.

Henrich, J., Heine, S. J. \& Norenzayan, A. (2010). The weirdest people in the world? Behavioral and Brain Sciences 33, 6I-I35.

Hoff, E. (2006). How social contexts support and shape language development. Developmental Review 26, 55-88.

Hoff-Ginsberg, E. (I99I). Mother-child conversation in different social classes and communicative settings. Child Development 62, 782-96.

Hudson, J. \& Kühner, S. (20I6). Fairness for children: a league table of inequality in child well-being in rich countries (Unicef Innocenti Report Card 13). Florence: Unicef Innocenti Research Centre. Online: <https://www.unicef-irc.org/publications/pdf/RCr ${ }_{3}$ eng.pdf $>$.

Huston, A. C., Duncan, G. J., McLoyd, V. C., Crosby, D. A., Ripke, M. N., Weisner, T. S. \& Eldred, C. A. (2005). Impacts on children of a policy to promote employment and reduce poverty for low-income parents: New Hope after 5 years. Developmental Psychology 4I, 902-I 8

INE (Instituto Nacional de Estadísticas) (2012). Resultados XVIII Censo de Población [Results XVIII of the population census]. Santiago de Chile. Government of Chile. Online: $<$ https://www.cooperativa.cl/noticias/site/artic/20130425/asocfile/20130425 I $90105 /$ resultados_ censo_20I2_poblacion_vivienda_tomosiyii.pdf>.

Isenberg, J. P. \& Quisenberry, N. (2002). PLAY: essential for all children (A position paper of the Association for Childhood Education International). Childhood Education 79, 33-9.

JUNJI National Council of Daycare Centers (2009). Balance de gestión integral, año 2009 [Annual balance of integral management]. Online: <http://www.dipres.cl/574/articles60662_doc_pdf.pdf $>$. 
Loeb, S., Bridges, M., Bassok, D., Fuller, B. \& Rumberger, R. W. (2007). How much is too much? The influence of preschool centers on children's social and cognitive development. Economics of Education Review 26, 52-66.

Love, J. M., Harrison, L., Sagi-Schwartz, A., van IJzendoorn, M. H., Ross, C., Ungerer, J. A., ... \& Chazan-Cohen, R. (2003). Child care quality matters: how conclusions may vary with context. Child Development 74, I०2 I-33.

Luijk, M. P. C. M., Linting, M., Henrichs, J., Herba, C. M., Verhage, M. L., Schenk, J. J., ... \& van IJzendoorn, M. H. (2015). Hours in non-parental childcare are related to language development in a longitudinal cohort study. Child: Care, Health and Development 4I, i i 88-98.

MIDESO (Ministerio de Desarrollo Social [Ministry of Social Development, Chile]) (n.d.). Nivel socioeconómico [socioeconomic level]. Online: <http://www.contablesytributarias. $\mathrm{com} / 20 \mathrm{I}$ 4/05/ingresos-por-quintiles-ano-2014.html>.

Nancy, M. (2013). Expressive One-Word Picture Vocabulary Test-four-Spanish Bilingual Edition (EOWPVT-4-SBE). Novato, CA: Academic Therapy Publications.

NICHD Early Child Care Research Network (2000). The relation of childcare to cognitive and language development. Child Development 71, 960-80.

NICHD Early Child Care Research Network (2002). Early childcare and children's development prior to school entry: results from the NICHD study of early childcare. American Educational Research Fournal 39, I 33-64.

NICHD Early Child Care Research Network (2005). Pathways to reading: the role of oral language in the transition to reading. Developmental Psychology 4I(2), 428-42.

Noboa-Hidalgo, G. E. \& Urzúa, S. S. (2012). The effects of participation in public child care centers: evidence from Chile. Fournal of Human Capital 6, I-34.

Norenzayan, A. \& Heine, S. J. (2005). Psychological universals: What are they and how can we know? Psychological Bulletin $\mathbf{1 3}$ (5), 763-84.

Piñeiro, A., Manzano, M., Inguanzo, G., Reigosa, V.Morales, A. \& Fernández, C. (2000). Adaptación y normación de la prueba de vocabulario Peabody en una muestra de sujetos cubanos [Adaptation and standardization of the Peabody Picture Vocabulary Test in a sample of Cuban subject]. Revista Cubana de Psicología r7, I47-53.

Preacher, K. J. \& Hayes, A. F. (2004). SPSS and SAS procedures for estimating indirect effects in simple mediation models. Behavior Research Methods, Instruments $\Xi^{\circ}$ Computers 36(4), 7 I 7-3 I.

Preacher, K. J. \& Hayes, A. F. (2008). Asymptotic and resampling strategies for assessing and comparing indirect effects in multiple mediator models. Behavior Research Methods 40, 879-9I.

Prevoo, M J. L., Malda, M., Mesman, J.Emmen, R. A. G., Yeniad, N., Van IJzendoorn, M. H. \& Linting, M. (20I4). Predicting ethnic minority children's vocabulary from socioeconomic status, maternal language and home reading input: different pathways for host and ethnic language. Fournal of Child Language 4r(5), 963-84.

Richman, A. L., Miller, P. M. \& LeVine, R. A. (I992). Cultural and educational variations in maternal responsiveness. Developmental Psychology 28, 6 I 4-2 I.

Rodriguez, E. T. \& Tamis-LeMonda, C. S. (20I I). Trajectories of the home learning environment across the first 5 years: associations with children's vocabulary and literacy skills at prekindergarten. Child Development 82, I058-75.

Segall, M. H., Lonner, W. J. \& Berry, J. W. (i 998). Cross-cultural psychology as a scholarly discipline: on the flowering of culture in behavioral research. American Psychologist 53( (10), I IOI-I IO.

Song, L., Spier, E. T. \& Tamis-Lemonda, C. S. (2013). Reciprocal influences between maternal language and children's language and cognitive development in low-income families. Fournal of Child Language 40, $\mathbf{1}-22$.

Soto, E. (2009). La escolarización de los mapuche de Chile y la nueva mirada del estado [Schooling of the Mapuche in Chile and the new perspective of the state]. XXVII Congreso de la Asociación Latinoamericana de Sociología. Asociación Latinoamericana de Sociología, Buenos Aires. Online: <http://cdsa.aacademica.org/ooo-o62/2277>. 
Tabachnick, B. G. \& Fidell, L. S. (1996). Using multivariate statistics, 3rd ed. New York: Harper Collins.

Walker, S. P., Wachs, T. D., Gardner, J. M., Lozoff, B., Wasserman, G. A., Pollitt, E., .. \& International Child Development Steering Group (2007). Child development: risk factors for adverse outcomes in developing countries. The Lancet 369, I45-57.

World Bank (2012). Monitoring basic opportunities throughout the lifecycle with the human opportunity index in Chile. Poverty Reduction and Economic Management Unit, Latin American and Caribbean Region (Report No.: 67654-CL). Online: <https://openknowledge. worldbank.org/handle/ıo986/i i 9 I 9 >.

Yeung, W. J., Linver, M. R. \& Brooks-Gunn, J. (2002). How money matters for young children's development: parental investment and family processes. Child Development 73(6), I $86 \mathrm{I}-79$. 